\title{
Lo Cotidiano Trascendente en una Epístola de Lope de Vega
}

\author{
Por Luis HeRnán RAMíRez
}

Trabajo premiado en el concurso litcrario convocado por la Facultad de Letras de la Universidad Nacional Mayor de Son Marces con motivo del cuorto centenorio del nacimiento de Lope de Vego.

En el momento culminante de la historia de la humanidad, en la encrucijada de los siglos XVI y XVII, cuando España empezaba a interpretarse a sí misma, aparece Lope de Vega (1562-1635) trazando la biografía literaria de su patria, cuya realidad sintió e inmortalizó en su téatro, mágica síntesis del quehacer hispano.

Lope no escribió sus memorias. No fue un poeta con diario, pero su vida"entera esfá reflejada en el torrente de su compleja producción inundada de lirismo, en el más hondo y humano sentido de este término:

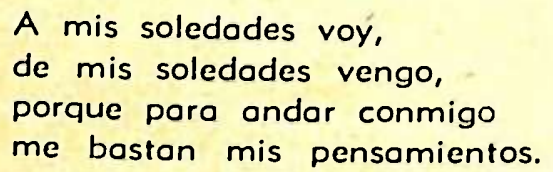

Lope comentaba en sus poesías toda su vida sentimental dejándonos, en ellas, puntuales noticias de su quehacer diario. Poeta de circunstancias, en el sentido goetheano de la palabra, la vida se le trasvasaba inconscientemente a sus escritos. Difícil encontrar en la literatura del mundo otro lírico, como Lope, en quien vida y poesía - vivir y crear, diría Entrambasaguas-aparezcan intimamente amalgamadas y recíprocamente estimuladas. La in- 
tegración de la biografía del Fénix de los Ingenios, desde Barrera - "Nueva Biografía de Lope", Madrid, 1890- hasta Zamora Vicente - "Lope de Vega", Madrid, 1961 - ha sido, en gran medida, el resultado de una exégesis minuciosa e inteligente de su obra.

H. A. Rennert y A. Castro que han realizado la más severa y acabada labor de acumulación, compulsa y reajuste de datos, así como de interpretación y análisis de las grandes zonas autobiográficas de la obra lopesca han lanzado esta verdad: "una parte de la producción poética de Lope surgió como glosa de los más importantes acontecimientos de su vida" (2). Pero, no sólo los acontecimientos importantes le suministraron materia poetizable. Toda su experiencia vital fue una experiencia poética, lo que hace de Lope un auténtico lírico. "La objetividad de este autor según anota Vossler, "no se manifiesta como una opinión determinada - como una determinada convicción, sino, esencialmente, como alegre desenvoltura, como puro goce de la vida" (3). Lo ordinario, lo menudo y cotidiano de la existencia humana vulneraba sutilmente su hipersensible temperamento lírico-dramático. Lope vivió de veras, vivió cada día, cada hora, cada instante para cumplir un destino práctico, inmediato. Sus amores y sus odios, sus ternuras y asperezas, sus mansedumbres y cóleras, sus frivolidades y misticismos le brindaron motivos que utilizó con na disimulado apasionomiento.

Como nuestro poeta abreva su lirismo en los azares y zozobras cle su vida, el conocimiento de esa vida se nos hace necesario para el goce estético de súscooemas ycel realce emocional de la calidad intrínseca de los mismos. Notas autobiográficas, referencias a la vida real y a su propia intimidad entran como formantes, como elementos estructurales en la lírica de Lope, particularmente en sus epístolas relegadas hoy, injustamente, a la lectura de lo eruditos que pueden situarlas en el tiempo y extraer de ellas datos para sus investigaciones. Si el lector actual no siente apetito do leerlas, no es que ellas hayan envejecido sino el género mismo que hoy se nos antoja falso y artificioso, no lo era en el siglo XVII. Los escritores de aquella época solían emplear con frecuencia este tipo de correspondencia lírica que adoptaba, por lo general, una forma grave y sentenciosa que no la encontramos en Lope. El Fénix no escribió epístolas morales sino vitales y ellas nos ponen frente $a$ un artista activo - no contemplativo- que necesita nutrirse de realidades concretas. Cultivó el género por lo que él tiene de íntimo, de coloquial. Estas cartas poéticas le permitían expre- 
sar mejor sus efectos refiriéndose, a veces, a los menesteres más nimios de su vida, sin rehuir, por cierto, ni las más complicadas formas del lenguaje ni los conceptos más sutilez. En la epístola a Don A.ntonio de Mendoza, incluída en "La Circe" (1624) escribe:

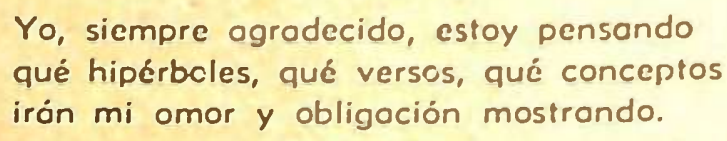

y en la dirigida a Don Juan de Árguijo, inserta en "La Filcmena" (1621) expone su idea acerca ciel género. Tan buscados son los conceptos e hipérboles, como la soltura, la ligereza y el desorden que acentúan el carácter misivo de este género:

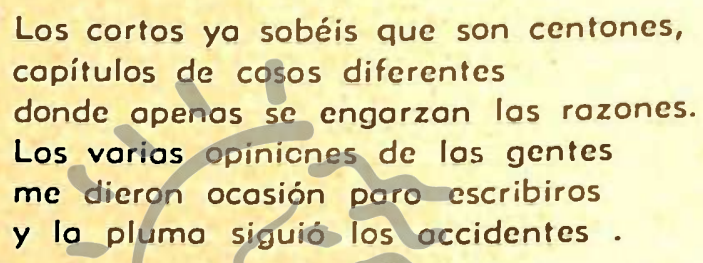

El encanto de sus epístolas reside, en opinión de Vossler (4) en el libre movimiento del poeta que se sabe vinculado a quien se dirige y quiere llevarle como de la mano de aquí para allá. En todas se adyierte una sabiduría sonriente, una suave ironía, algún breve humor y algo que convierte su pueril falta de objetividad

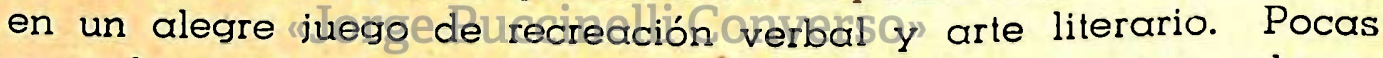
veces ha mostrado Lope más vivacidad, más abundancia y, al mismo tiempo, mayor exactitud y precisión de lenguaje que en sus epístolas.

Con estas consideraciones y sin ánimo de lagotar ahora una interpretación nos proponemos comentar la epístola que, en 1621. dirigió a la Amarilis Indiana, discutida incógnita de nuestra literatura colonial (5).

En los acompasados tercetos de esta epístola, Lope se sintoniza con su propia vida, vibrando en cada verso con una nota consonante en la sinfonía del mundo que lo envuelve y le toca vivir. La respuesta de Belardo a la "silva" de la supuesta huanuqueña resulta algo así como una breve biografía o anecdotario referido de modo encantador y hasta con una buena dosis de cinismo, como en la escena de los celos y reconciliación de sus padres que nos recuerda el villano origen de los héroes de la picaresça; 


\begin{abstract}
vino mi padre del solar de Vega, asi a los pobres la nobleza exhorta. siguióla hasta Madrid, de celos ciega, su amorosa mujer, porque él querio una española Elena, entonces griega; hicieron amistades $y$ oquel dio fue piedra en mi primero fundamento la paz de su celosa fantasio.

En fin, por celos soy, iqué nocimiento! imaginadle vos, que haber nacido de tan inquieta cousa fue portento.
\end{abstract}

En el fondo Lope no se propone otra cosa que entretener a lo que viviendo en "limpio celibato" le confesaba su "amor sin esperanza". De allí la variedad desordenada de su relato dando cuenta a la desconocida, de su origen, sus padres y linaje, de sus es tudios y precocidad literaria, ae sus matrimonios e hijos, de su ordenamiento y soledad:

Lo confusión o veces me fastidio, y aunque vivo en lo Corte, estoy más lejos que está de la Moscovio la Numidia.

Tócanme solamente los reflejos de los grandes palacios a mis ojos más solos que los hayos y los tejos

de sus simpatías y pojerizas, de sus preōcupaciones y arrepentimientos:
Lo que entonces medré mi edad to siente."
Los dulces versos tiernamente han sido
piodoso culpo en los primeros años
iAy si los viera yo cubrir de olvido!

Lope trata, igualmente, de influir en el ánimo, cuando no en las decisiones de la poetisa enamorada; por eso, respondiendo a su preocupación de celos le escribe:

$$
\begin{aligned}
& \text { Cantad su vida vos, pues que se emplea } \\
& \text { no la temais, que Celias de la tierra } \\
& \text { a ser infiernos de las almas vienen. } \\
& \text { Si tanta tierra y mar el paso cierra } \\
& \text { a celos, y no a amor imaginado, } \\
& \text { huya de nuestro paz tan fiera guerra. }
\end{aligned}
$$

Y sobre el pedido de poner en versos la vida de Santa Dorotea, Lo. pe muy cortésmente se niega diciéndole; 
Cor.tad su vido vos, pues que se emplea

virgen sujeto en costo pensamiento,

pera que el mundo sus grondezos vea,

que vuestro celestiol entendimiento

le do.á glorio acidentol contando

entre los luces del empirio osiento.

y concluye la epístolu incitando el entusiasmo poético de la india. na:

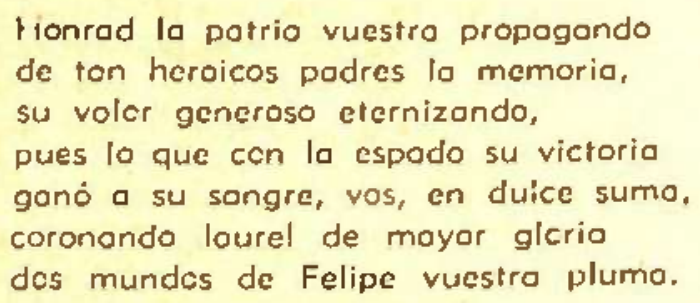

obsérvese el valor persuasivo de los imperativos cantad y honrad en los dos últimor fragmentos.

No hay en la epístola un plan determinado, los motivos poetizados se suceden en desorden, y aunque los tópicos de la sincesridad y la confidencia están a menudo presentes, parece no animarle, aquí, ninguna pasión dominante como en otras epístolas, lo que nos lleva a pensar que fuera escrita un poco de compromiso; de allí la perplejidad manifiesta en los versos iniciales; de alli, las repetidas interrogantes (¿qué os diré de mí? ¿cómo podré yo veros ni escribiros?), de alli, en fin, ese Constante apelar al recurso sencillo y concluyente de là exclamación \&"c̈iqué clara, qué copiosa y dulce sumal", "iqué rica telal", "itriste sucesol", elc.).

Por compromiso, Lope abunda en elogios:

Nunca la hermoso vida de su dueño

voroz el tiempo consumir presuma.

Asi yo, penentrando la luz pura

de vuestro sin igual entendimiento.

y pondera la habilidad poética de Amarilis hasta el extremo de to. marla como modelo:

openas de escribiros hollo el modo,

si bien me lo enseñáis en vuestros versos

a cuyo dulce estilo me acomodo, 
y de paso extiende su elogio a los ingenios de Indias:

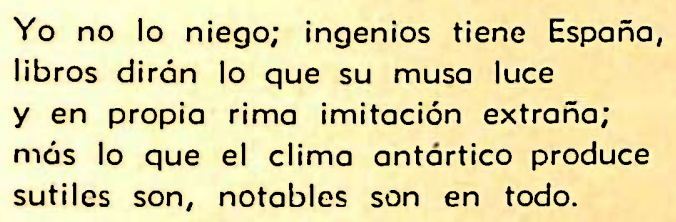

Lope se ve en el compromiso también de adornarse de buenas cualidades y hacer gala de buenas costumbres:

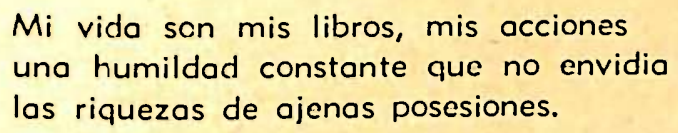

Obligado, por decirlo así, a corresponder el amor desinteresado de su lejana y recatada admiradora, sus palabras toman cierto aire académico y artificial de quien sin sentir hondamente una pasión debe fingirla a riesgo de parecer ingrato o desleal:

$$
\begin{aligned}
& \text { amo naturalmente a quien me amo } \\
& \text { y no sé aborrecer (a) quien me aborrece, }
\end{aligned}
$$

y luego de una larga disquisición en torno al amor distante no tiene reparos en manifestar, así, su amor, con un lenguaje muy solemne y ceremonioso, como quien hno tiene' ya otra alternativa:

$$
\begin{aligned}
& \text { "Jorge Puccinelli Converso" } \\
& \text { si me decís quién sois y que previene } \\
& \text { un platónico amor vuestro sentido } \\
& \text { que a provocaros desde España viene, } \\
& \text { para quereros yo licencia os pido, } \\
& \text { que dejaros de amar injurı fuera, } \\
& \text { por eso mismo que de vos lo he sido. }
\end{aligned}
$$

y al final de una esquemática relación de su vida y sus pesares, Lope consciente de su obligación de amar estampa estos reveladores versos:

De mi vida, Amarilis, os he escrito lo que nunca pensé, mirad si os quiero, pues tantas libertades me permito.

El autor de "La Dorotea", amante empedernido, con una inveterada afición por mujeres casadas o comprometidas, no podía 
vibrar con el amor platónico. Qué lejos estaba Lope de Petrarca o de Dante en su actitud amorosa. Esta incapacidad de nuestro poeta para el amor platónico le hace caer en el artíticio, en la pura retórica, como en aquellos juegos de palabras y conceptos, no de muy buen gusto, que encontramos en el terceto inicial, con el significado de "otro mundo"

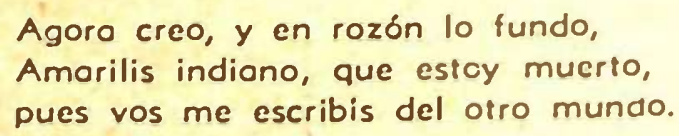

y más adelante con la polisemia del verbo "ordenar"

\section{ordeneme, Amorilis, que importabo \\ el ordenorse o lo desorden mío}

Un aspecto importante, que no podemos pasar por alto al comentar la epístola, es el ágil cambio de estilo que lo anima desde el más simple y claro hasta el más complicado y oscuro. Aqqui, como en toda su obra cuando se empeña en transformar en arte superior los elementos populares, Lope incursiona en los dominios del culteranismo y el conceptismo, pero culteranismo y conceptismo no constituyen un rasgo fundamental de su estilo, desempeñan solamente un papel ornamental que no afecta la gravedad de su rc:zonamiento. Son expresiones líricas tcomo éstas: "pues desde el mar del sur naye de pluma" " "vos de la línea equinoccial sirena". "escribía con pluma por cortar versos del nido" "y todo el goilo del mayor Nereo", etc., que nada pierden junto a la suprema ciistinción de los versos de Góngora, o como estas otras: "donde el amor es alma, el cuerpo es sombra" "si el alma es posesión la fe, esperanza". "no pierdo triste, ni contento gano", etc., que el propio Quevedo envidiaría. Estos elementos decorativos sólo marccin un límite sensorial, no llegándole jamás hasta el alma porque su visión poética alcanza inmejorable colorido y halla su máxima validez en el perfecto equilibrio y armonía del epíteto y ritmo clásicos que vienen de Garcilaso y Herrera: ("a cuyo dulce estilo mo acomodo". "en mares tan remotos y diversos". "penetrando la luz pura". "tendré mas sol en noche más oscura" "sobre blanda espuma", etc.). Con justificada razón, Dámaso Alonso concluye una nota sobre el barroquismo de Lope con estas palabras: "esa pluralidad vital de su estilo que nunca se aquieta en perfección lograda, se nos convierte en símbolo barroco" (6). 
En "Belardo a Amarilis" el tópico de la intimidad se enlaza con el de la sinceridad. Lope se ha propuesto contarle a la poetisa peruana, partes de su azarosa vida sin la menor intención de ocultarle o mentirle nada,

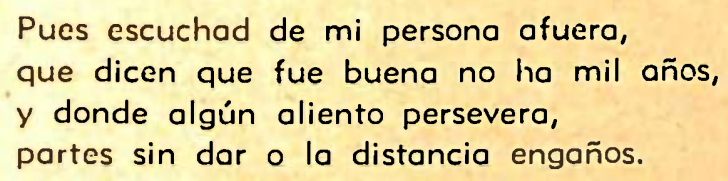

Pues escuchad de mi persona afuera, que dicen que fue buena no ha mil años, y donde algún aliento persevera, partes sin dar o la distancia engaños.

$y$ aferrándose a todo lo que en ese momento le era familiar y querido, incluyendo la calaverada paterna y su propio ordenamiento, empieza el relato de los aspectos más importantes de su vivir cotidiano en versos impregnados de los jugos vitales de su experiencia, transparentándonos toda su pluralidad, no sólo sus desenfrenos y arrepentimientos, sus amores y sus odios ya conocidos, sino, nuevos aspectos no siempre revelados, como su perfil picaresco - alusión a su nacimiento- o la ternura humanísima de su corazón tan grande - la memoria de sus muertos queridos-. He aquí el itinerario lírico de su trayectoria vital en la epístola.

\section{VINO MI PADRE DEL SOLAR DE VEGA}

Lope se pagó del achaque español de los siglos XVI y XVII, el de ostentar noblezđay çreen què lal sangre másnoble de España procedía de las montañas de Asturias:

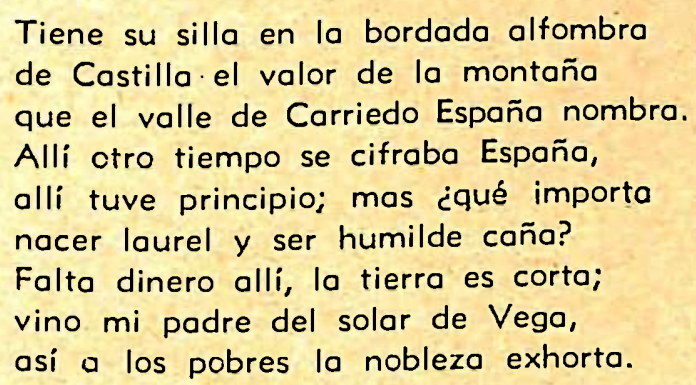

Lope no soslayaba su humilde situación. Le interesaba -auténtico español del siglo XVII- señalar únicamente la limpieza de su origen ("¿qué imporia nacer laurel $y$ ser humilde caña?"). Se complace de contar entre sus ascendientes gentes honradas, afincadas durante varias generaciones en una casa de Vega del Ca- 
rriedo. Por eso, cuando se atribuyó el escudo de Bernardo del Carpio que estampó con sus diecinueve torres, en la portacla de "La Arcadia" (1598) se cuidó bien de poner esta leyenda: "De Bernardo es el blasón, las desdichas mías son", y con plena conciencia de su modestia insistía en carla al Duque de Sesa: "Naci hombre de bien de un pedazo de peña en la montaña". A pesar de estas repetidas muestras de modestia nuestro poeta no escapó a la sátira cruel de Don Luis de Góngora:

Por tu vida, Lopillo, que me borres

los diez y nucve torres de tu escudo; pues ounque tienen mucho viento, dudo que tengos viento paro tontos torres.

\section{FUE PIEDRA EN MI PRIMERO FUNDAMENTO}

Es muy verosímil, segúm anotan sus biógrafos que en la decisión que tomara el padre de Lope de instalarse en Madrid influyera la circunstancia de haberse trasladado allí la Corte en 1560. Un bordador fino como Don Félix de Vega no habría podido desenvolver con holgura su oficio en aquellas montañas astures, "falta dinero alli, la tierra es corta". pero inteligentemente, Lope soslaya la alusión aboficio paterno con un incidente amoroso:

\section{"Josiguióleuhostal Madrid,1déecelos" ciego, su amoroso mujer, porque él quería uno españolo Eleno, entonces griega;}

circunstancia retórica que permite al apasionado amante recordur, una vez más, el nombre, grato a sus aventuras juveniles, de Elena Osorio, primera musa de su ascendrada poesía lírica a quien entregó a torrentes su producción teatral y, más tarde riñendo con ella y su familia, llevó su rencor hasta el libelo y la difamación que le valieron diez años de destierro de la Corte. Según el mismo cuenta, su nacimiento se debe a un pacto de amor y celos de sus padres:

\footnotetext{
hicieron amistades $y$ aquel dia

fue piedro en mi primero fundomento

la paz de su celosa fontasio.
}

Quien siga la agitada vida amorosa de Lope no podrá dejar de recordar a este Félix de Vega corriendo tras una bella dama 
alegre y pagana, como un bravo antecedente del hijo que osó violar el destierro con su amenaza de muerte para raptar a una novia (Isabel de Urbina) desposándola romántica y temerariamente, y que, ya en el puerto seguro de la vejez, siente de nuevo estallar en su alma la más espantable tormenta amorosa de toda su vida (Marta de Nevares).

\section{LLEGO LA EDAD Y DEL ESTUDIO EL DIA}

A su propia precocidad, fantásticamente exagerada por su discípulo Pérez de Montalbán, alude con fino humorismo:

y continúa con claras alusiones a sus estudios:

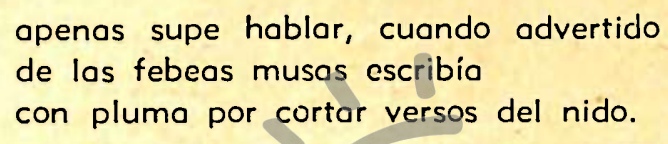

Este aspecto de su vida ha sido ampliamente revisado y confrontado por todos sus críticos y biógrafos y cada uno de ellos ros ofrece una solución más o menos admisible, más o menos congruente y verosímil sobre dónde estudió y su grado de cultura. Por ellos sabemos hoy que Lope estuvo en los teatinos, en el Colegio Imperial de la Compañía, en Alcalá de Henares, que estudió matemáticas, el astrolabio y la esfera en la Academia Real, que escuchó lecciones del cosmógrafo portugués Juan Bautista Labaña, que recogió enseñanzas de Ambrosio Ondériz, de su cuñado Luis Rosiquel y del maestro Juan de Córdova, que se inició en poesía imitando a Vicente Espinel, que sabía latín y otras lenguas:

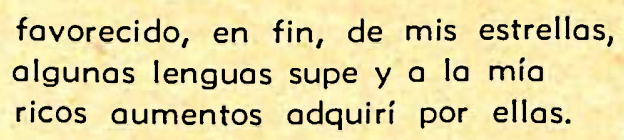


sabemos que leyó a sus contemporáneos y comentó a San Aguslín y a Cicerón, pero sus libros principales fueron el de la naturaleza y el de la pasión que no se estudian en las universidades ni colegios. Lope tuvo siempre la manía de aparenlar una gran cullura. En esta epístola encontramos un notorio afón de erudición cuando echa mano a sus conocimienlos de astronomía para hablar de los años:

siete veces el sol retrocedía

desde lo octava parte al Cancro fiero

igualando lo noche con el dia.

Las alusiones a sus estudios nos permiten conocer por qué la formación de Lope, pronto abandonada $\alpha$ su albedrio no se sujetó a un plan ordenado. Nos informa que abandonó sus estudios por causa del amor:

Amor, que omor en euonto dice miente, me dijo que a seguirle me inelinase.

Pero no fue sólo el amor. También contribuyó a agobiarle, en tan temprana edad, el embarazoso e inútil lastre de un saber $y$ un pensar esencialmente rnedievales:

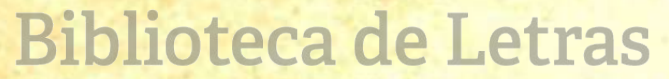

Aqui luego engaño imi pensamiento

Roymunda Lulio, laberinto grove.

rémoro de mi corto entendimiento.

a todo esto hay que agregar la indolencia del muchacho como causa perturbadora de sus estudios regulares:

Quien por sus cursos estudiar no sobe

no se fie de cifras......

..... que yo importuno

se me mostraba con la flor ardiente

cualquier trabajo y no admiti ninguno.

Una vez más la sinceridad de Lope manifestada por la vida confidencial. 


\section{DE SUS COSTUMBRES SANTAS HICE HISTORIA}

Lope fue un enamorado crónico. No tuvo como algunos seres felices una pasión única, exclusiva y excluyente, noble y sublime. Tuvo amores hondos y en cada pasión encontró furia, tormentos y sorpresa. Supo alternar, a la largo de sus romerías amorosas, sus millones de versos, sus arrepentimientos y delirios con escándalos, cárceles, deudas y desafíos. Los más diversos matices del amor que se logra y se pierde se perciben en su vida: Filis (Elena de Osorio) es la tensión celosa; Belisa (Isabel de Urbina), el remanso de la ternura; Jacinta (Juana de Guardo), la serenidad; Camila Lucinda (Micaela Luján) le arrastra al paroxismo de la lujuria y Amarilis (Marta de Nevares) le trae el estímulo cordial en las horas otoñales.

El amor determina la temperatura humana de su vida $y$ de su obra. Su forma vital y poética siguió la forma de su amor. Se ha alegado la versatilidad amorosa de Lope para imputarle un donjuanismo cínico y frívolo, que es/el polo opuesto de su tipo vital. Aunque conoció y simultaneó muchas mujeres no fue un versátil propiamente, no saltó de una aventura a otra, no alternó amores efímeros e insustanciales. En cada caso se entregó totalmente con esa ceguera lúcida o alucinante de la pasión y en cada caso padeció y gozó y supo cie la angustia y del deleite eróticos. No le arrastró hacia la mujer el mero deseo carnal primario y transitorio, sino un anhelo superior de comunicación espiritual, cordial.

En esta epístola Lope se refiere únicamente a sus dos amores lícitos ante el altar de Dios y el mundo: Isabel de Urbina y Juana de Guardo:

\footnotetext{
Dos veces me casé, de cuya empresa sacaréis que acerté, pues porfiaba, que nadie vuelve a ver lo que le pesa.
}

Con el recuerdo de sus esposas muertas, Lope compuso en más de una oportunidad, conmovedoras páginas. En el aniversario de la muerte de su primera mujer compuso un plañidero romance primaveral que empieza con estos hermosos versos:

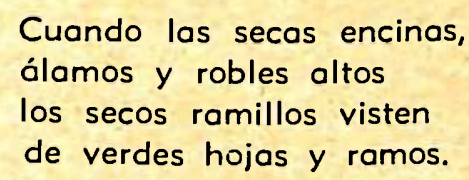


y cuya última estrofa nos muestra un Lope distinto al que suelen representarnos sus biógrafos:

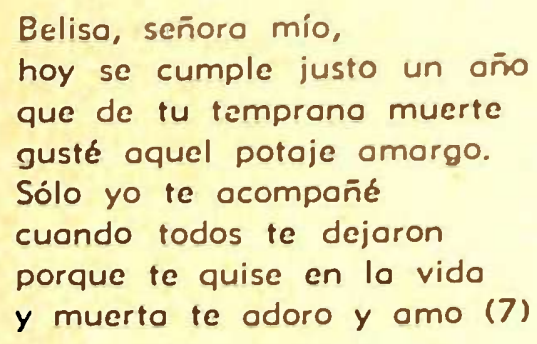

En la epístola que comentarnos, Lope al aludir a su hija Feliciana tiene oportunidad para llorar la desaparición de Doña Juana recordando con justificada gratitud y pena su abnegación de madre y su bondad de esposa:

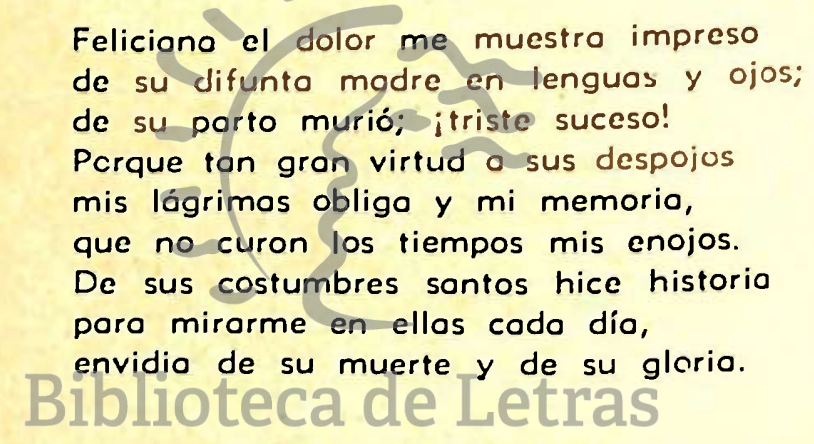

\section{DEJE LAS GÁLÂS QUE SEGLÂR VESTì}

Tras la muerte de Juana, Lope se siente invadido por un hondo fervor místico y busca salvar esos momentos críticos de su vida con una suprema creación estética donde combina el amor desordenado con los arranques de una pasión más intensa y escribe "Los pastores de Belén" (1612) y "Rimas Sacras" (1614) y, con-la misma energía con que amó, con la misma intensidad con que supo cantar los bellos ojos azules de Micaela y los encantos múltiples de Filis se eleva a los arrebatos del más violento amor místico y desea hacerse sacerdote. A los 52 años recibé órdenes religiosas, en su alma se había producido una honda crisis de sentimentalidad y romanticismo. Refugio, seguridad, garantía es lo que buscaba con patético afán en el sacerdocio.

Dejé los golos que seglor vestio; 
ordenéme, Amarilis, que importaba

el ordenarse a la desorden mía.

"ordenarse" era ordenar su vida, poner orden en su desorden. Pero Lope es también un buen padre de familia y antes de ordenarse recoge a todos sus hijos, legítimos y adúlteros, y los lleva a vivir juntos bajo el mismo techo.

\section{UN HIJO TUVE EN: QUIEN MI ALMA ESTABA}

Lope tuvo muchos hijos, los varones fueron por el mundo como exploradores, capitanes o frailes; las hembras profesaron, se casaron o fugaron de la casa paterna con el primer amante, pero a todos les prodigó el mismo cariño. Lo más hermoso y tierno do la epístola a Amarilis lo encontramos, precisamente, en las alusiones a sus hijos, Carlos, Lope, Marcela, Feliciana.

Carlillos, nacido en su segundo matrimonio ganó hondamente el corazón del viejo Lope. Al lado de este niño y de su madre el poeta debió pasar días muy felices a juzgar por los términos de esa magnífica descripción de su vida doméstica que nos ha dejado en la epístola al Dr. Matías Porras:

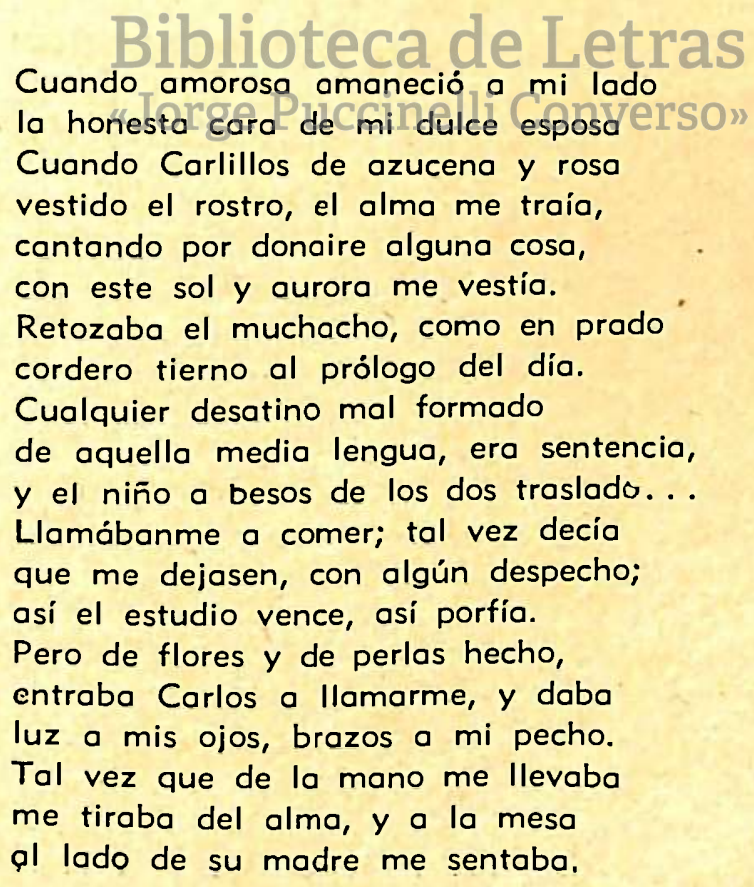


Qué sinceridad en este delicioso y delicado cucriro interior de su felicidad hogareña donde se dan la mano sus tres amores: sin mujer, su hijo y las tres letras. Pero esta dicha se interrumpe bruscamente con la muerte de su hijo en 1612. Angustiado, Lope escribió una elegía -a la que hace referencia en la epístolaque es, sin duda, la más desgarradora e inolvidable de las elegías castellanas, con qué ternura recuerda allí cómo quería distraer al pequeñín con pajaritos y flores:

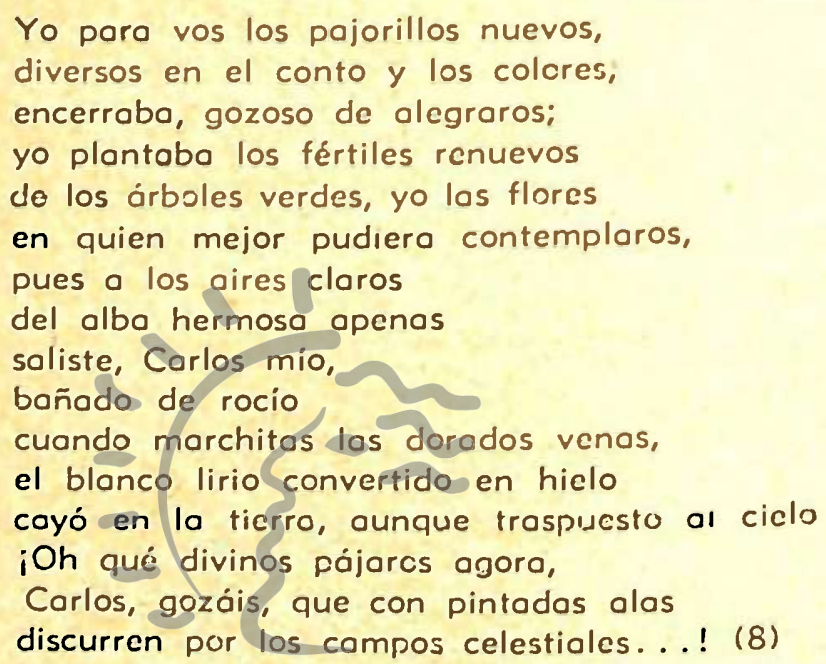

Han transcurtiat qa ochoaños de sumuerte y Lope vuelve a recordar a su jufantep en les terfelos reásoemocionc. dos de la cpístola a Amarilis.

\footnotetext{
Un hijo tuve en quien mi almo estabo, allo tombién sobréis por mi elegio que Carlos de mis ojos se llamabo. Siete veces el sol retrocedio desde la octovo parte al Cancro fiero, igualando la noche con el día, - círculos menores lisonjero, $y$ el de su nocimiento me contabo, cuando perdió la luz mi sol primero, alli murió la vida que onimabo la vida de Jacinto. ¡Ay muerte fiera! lo flecho erraste al componer lo aljabo. Cuanto fuera mejor que yo muriera que no en los principios de su ouroro ¡Corlos tan larga noche padeciera!
} 
Le quedaba otro hijo, el de Micaela Luján, nacido en 1607:

Lope quedó, que es el que vive agora.

Lope el mozo sale un poco al padre, es díscolo, voluntarioso y rebelde. Se aficiona a los versos y participa, con éxito, en el certamen poético realizado con motivo de la canonización de San Isidro en 1620, pero abandona las letras por las armas:

¿No estudia Lope? ¿Qué queréis que os diga, si él me dice que Marte le enamoro?

Enrolado en los tercios de Italia luchó contra holandeses y turcos. Lope se sentía orgulloso de él en la epístola a Don Francisco de Herrera y Maldonado ("La Circe"). Pudo haber sido un gran capitán pero su inquietud lo llevó a las costas de Venezuela y de allí a pescar perlas en las Islas Margaritas donde pereció trágicamente en un naufragio. En una égloga ("La Vega del Parnaso" - 1637) Lope nos cuenta con gala y aderezo literarios el trágico fin de este hijo.

Marcela, otra hija de Micaela, conquistó por igual el cariño y la confianza del padre. Lope le dedicó cuando cumplía quince años una de sus comedias: "El Remedio de la Desdicha" y le confió la escabrosa e indigna tarea de sustraer con maña, a su Amarilis, las cartas de amor quéél le escribía, lás mismas que debía reunir y ordenar limpiamente para delite del Duque de Sesa (el de Sesa sin seso, como decía Quevedo).

Marcela que, como su hermano, había heredado la vena poética de su padre se sintió más inclinada a la vida religiosa:

\footnotetext{
Marcela con tres lustros ya me obliga

a ofrecérsela a Dios, a quien desea, si él se sirviere que su intento siga.

Aqui, pues no ha de haber nadie que crea

amor de un padre, no es decir exceso

que no fue necia y se libró de fea.
}

Cumpliendo sus deseos ingresó en el Convento de las Trinitarias Descalzas. Lope describe con ternura y melancolía este suceso en la epístola a Don Francisco de Herrera. Un fidelísimo vínculo cordial le mantuvo unido, por el resto de sus días, a Sor Marcela de San Félix. Con este nombre vivió su hija en el con- 
vento hasta los ochentaitrés años de edad; no se supo allí çue era hija del gran poeta o se había olvidado con buena voluntad. Lope ya investido del traje sacerdotal prefería decir sus misas, alli, en la Iglesia de las Trinitarias, donde tras la reja su hija rezaba con él.

Con la profesión de Marcela, con el naufragio de Lopillo, con la ceguera y muerte de Doña Marta de Nevares y finalmente con la fuga de Antoñica, su último retoño, Lope de Vega, que lle gó a ser símbolo de su pueblo y de su patria, alcanzó, en el ocaso de su accidentada vida, la grandeza de un Edipo. La pobre Feliciana, hija legítima, que representaba en el hogar de Lope la fealdad honesta y humilde fue la llamada a atender y a servir a su padre en sus últimos momentos.

\section{NOTAS :}

(1) Incluida en "Lo Dorotea" (1632).

(2) HUGO RENiVERT Y AMERICO CASTRO. Vida de Lope de Vega. Madrid, 1919, p. 39.

(3) KARL VOSSLER. Lopo de Vega y su Tiempo. Madrid, 1940, p. 133.

(4) K. SOSSLER. Ob. cit., p. 178 .

(5) Lo epistola "Belardo a Amarilis' fue publicada por primera vez en "Lo Filomena". Madrid, 1621. Paro este trabajo hemos utilizodo el texto que trae el tomo ll de Pecsius Líricas de Lope de Vega. Colec. Clásices Castellanos, vol. 75. Modrid, 1941, pp. 94-101.

(6) DAMASO. ALONSO. Pocsía Española. Madrid, 1950.

(7) Incluida en "Romancero General" (1600).

(8) Incluida en "Rimas Socras" (1614). 